\title{
Infrared Spectra of Poly(acetylene)
}

\author{
Hideki Shirakawa and Sakuji IKeda \\ Research Laboratory of Resources Utilization, \\ Tokyo Institute of Technology, Ookayama \\ Meguro-ku, Tokyo, Japan.
}

(Received November 9, 1970)

\begin{abstract}
The infrared spectra of poly(acetylene), poly(acetylene- $d_{2}$ ), copoly(acetylene +acetylene- $\left.d_{2}\right)$, and copoly(acetylene +acetylene- $d_{1}+$ acetylene- $\left.d_{2}\right)$ prepared by the $\mathrm{Ti}\left(\mathrm{OC}_{4} \mathrm{H}_{9}\right)_{4}-\mathrm{Al}\left(\mathrm{C}_{2} \mathrm{H}_{5}\right)_{3}$ system over a wide temperature range (ca. -100 to $180^{\circ} \mathrm{C}$ ) are reported. A tentative assignment of the observed spectra is made on the basis of model structures in which infinite planar chains of all trans, all trans-cisoid, and all cistransoid configurations are assumed. The spectral data are best interpreted on the basis of an all cis-transoid (or an all trans-cisoid) structure for the polymers prepared at temperatures lower than $-78^{\circ} \mathrm{C}$, and an all trans structure for the polymers prepared at temperatures higher than $150^{\circ} \mathrm{C}$.

Simplified calculations of the C-H and C-D out-of-plane deformation frequencies are made for various model chains. It has been concluded from a comparison of the observed and calculated frequencies that the cis-opening of the triple bond occurs in a polymerization reaction with the $\mathrm{Ti}\left(\mathrm{OC}_{4} \mathrm{H}_{9}\right)_{4}-\mathrm{Al}\left(\mathrm{C}_{2} \mathrm{H}_{5}\right)_{3}$ catalyst system at low temperatures.

KEY WORDS Infrared Spectra/Poly(acetylene)/Deuterated Acetylene/ Ziegler Catalyst/Configuration/cis-Opening/Factor Group Analysis/ Normal Vibration/
\end{abstract}

Structure and properties of poly(acetylene) prepared with Ziegler-Natta catalysts have been investigated by several groups. Natta, et al., ${ }^{1}$ presented evidence from chemical properties and $X$-ray diffraction data, indicating that the poly(acetylene) obtained had linear chains of conjugated double bonds of trans configuration along the chains.

A characteristic band at $9.86 \mu\left(1010 \mathrm{~cm}^{-1}\right)^{2,3}$ in the spectra of poly(acetylene) has been assigned to the out-of-plane deformation vibration of hydrogens attached to trans carbon-carbon double bonds. Watson, Jr., et al., ${ }^{2}$ observed a band at $14.13-14.9 \mu$ in the spectrum of a polymer prepared from a triisobutylaluminum-titanium tetrachloride system. The band was assigned to the cis $\mathrm{C}-\mathrm{H}$ out-of-plane deformation vibration. From the interpretation of the spectra, they suggested that the polymer obtained from triisobutylaluminum contained both cis and trans configurations along the polymer chain whereas the polymer prepared with $n$-butyllithium was predominantly trans. Recently, Kleist and Byrd, ${ }^{14}$ have reported a preparation of cis rich poly(acetylene) containing a $60-70 \%$ cis content obtained by a catalyst system of thermally decomposed iron dimethylglyoximate-2-pyridine and triethylaluminum at $25^{\circ} \mathrm{C}$ or below.

In this paper, we wish to report the analysis of normal vibrational modes, to make tentative assignments of observed bands in infrared spectra of poly(acetylene), poly(acetylene- $\left.d_{2}\right)$, copoly(acetylene + acetylene- $d_{2}$ ), and copoly (acetylene + acetylene- $d_{1}+$ acetylene- $d_{2}$ ) and to discuss these results in relation to the structures of the polymers.

\section{EXPERIMENTAL}

\section{Reagents}

Acetylene was purified before use by being passed successively through a sodium hydrogensulfite solution, a Dry Ice-methanol trap, a calcium chloride column, a phosphorus pentoxide column, and finally a tetralin solution of triethylaluminum. Acetylene- $d_{2}$ was prepared by adding heavy water (99.75-mol\% isotopic purity) to calcium carbide pretreated at $800-900^{\circ} \mathrm{C}$ under 
vacuum for about $3 \mathrm{hr}$. Mass spectroscopy indicated that the deuterated acetylene contained 99.23 mol $\%$ of acetylene- $d_{2}$ and 0.77 mol $\%$ of acetylene- $a_{1}$. A mixture of acetylene- $d_{0},-d_{1}$, and $-d_{2}$ was prepared by using a mixture of light and heavy water. The distribution of deuterium in the mixture was checked by mass spectrum. Titanium tetrabutoxide and triethylaluminum were used as purchased. Solvents were dried and distilled under nitrogen.

\section{Preparation and Measurement}

Poly(acetylene), poly(acetylene- $\left.d_{2}\right)$, copoly(acetylene + acetylene- $d_{2}$ ), and copoly(acetylene + acetylene- $d_{1}+$ acetylene- $d_{2}$ ) were prepared in the form of thin films by introducing acetylene gas to an unstirred concentrated solution of the $\mathrm{Ti}\left(\mathrm{OC}_{4} \mathrm{H}_{9}\right)_{4}-\mathrm{Al}\left(\mathrm{C}_{2} \mathrm{H}_{5}\right)_{3}$ catalyst system or to a reaction vessel in which a concentrated solution of the catalyst was spread over the glass wall to form a polymer film on the surface of the solution. In order to control the thickness of films, the polymerization was interrupted by evacuating the system. Polymerization was carried out at several temperatures over a wide range of $c a$. -100 and $180^{\circ} \mathrm{C}$. At polymerization temperatures lower than $80^{\circ} \mathrm{C}$ toluene was used as solvent, whereas at temperatures higher than $80^{\circ} \mathrm{C} n$-hexadecane was used. The films obtained were washed repeatedly by toluene, until the solution became colourless. Purification of the films was carried out at the same temperature as the polymerization temperature in order to prevent cis-trans isomerization of the polymers. The purified films were spread on a copper mesh and dried by blowing nitrogen gas on them at room temperature for a few minutes. All the processes were carried out under an atmosphere of nitrogen in order to prevent the oxidation of the polymers. Although the spectra were recorded in the air at room temperature, no spectral change was observed during a few successive scannings.

The infrared spectra were recorded by a Japan Spectroscopic Co. Model IR-G double beam grating spectrophotometer and a Hitachi Model EPI-G3 double beam grating spectrophotometer in the region of $4000-400 \mathrm{~cm}^{-1}$.

\section{ANALYSIS OF NORMAL VIBRATION FOR MODEL STRUCTURES}

It has been considered that poly(acetylene) prepared by Ziegler-Natta catalysts is a linear molecule having as many conjugated double bonds as the degree of polymerization. Lennard -Jones studied the linear polyenes of the general formula $\mathrm{C}_{2 n} \mathrm{H}_{2 n+2}$ by the LCAO molecular orbital theory and found that as $n$ increases, alternate bonds tend to become nearly equal with a length of $1.38 \AA .^{7} \quad$ This theory has been accepted for a long time. Corradini ${ }^{4}$ estimated the length of the C-C bond to be $1.40 \AA$ from the calculated resonance energy of poly(acetylene).

Kuhn, ${ }^{8}$ however, found that the observed absorption spectra of polyenes could only be interpreted by the free-electron theory if the bond length were supposed to alternate throughout the chain, even in very long chains. Ooshika, ${ }^{9}$ using the self-consistent LCAO molecular orbital

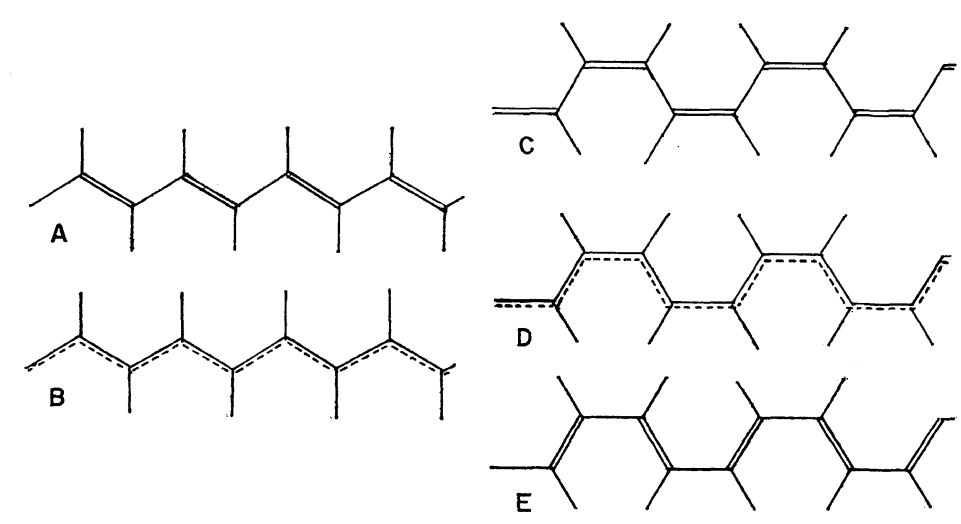

Figure 1. Possible structures of poly(acetylene). 
theory, found that the equilibrium configuration with all bond lengths equal to $1.389 \AA$ was less stable in the limit than one in which alternate bonds were of the length of 1.346 and $1.463 \AA$ based on the semi-empirical evaluation of several energy integrals. The calculation concerns an infinitely large conjugated cyclic polyene $\mathrm{C}_{2 n} \mathrm{H}_{2 n}$,

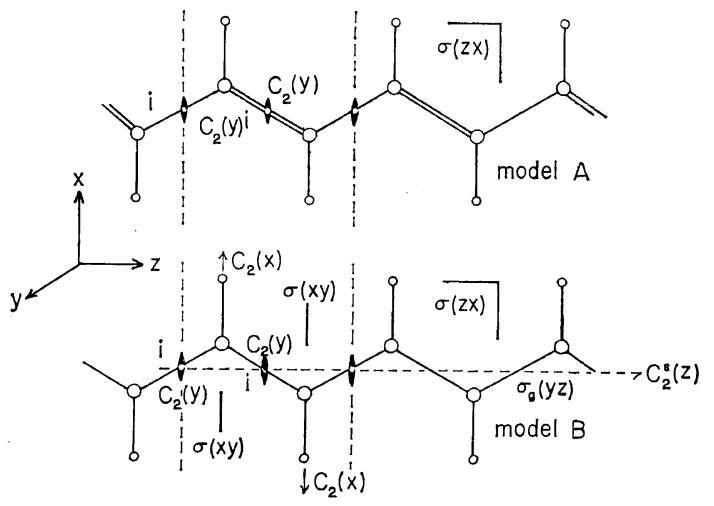

Figure 2a. Unit cells and symmetry elements of models A and B. Unit cell is shown between thin broken lines.

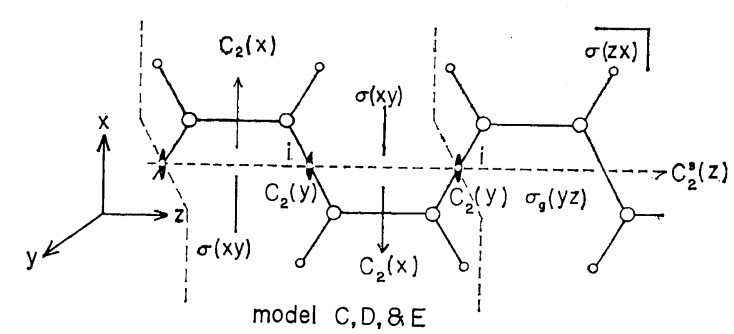

Figure 2b. Unit cell and symmetry elements of models C, D, and E. Unit cell is shown between thin broken lines.

the result of which is also applicable to an infinitely long linear polyene.

Stability of the polyene molecule depends upon the resonance energy associated with the conjugated double bond system. In order to have the maximum amount of resonance stabilization, the structure of the molecule must be planar.

The possible structures are shown in Figure 1. In these models, $\mathrm{A}$ and $\mathrm{B}$ have trans-transoid skeletons whereas $\mathrm{C}, \mathrm{D}$, and $\mathrm{E}$ have cis-transoid or trans-cisoid backbones. In B and D, all C-C bonds are equal in length.

Table I. The character table for the point group $\mathrm{C}_{2 \mathrm{~h}}$, symmetry species, selection rules, and number of normal modes for model $\mathrm{A}^{\mathrm{a}}$

\begin{tabular}{llrrrrrrrr}
\hline $\mathrm{C}_{2 \mathrm{~h}}$ & $\mathrm{E}$ & $\mathrm{C}_{2}(\mathrm{y})$ & $\mathrm{i}$ & $\sigma(\mathrm{zx})$ & $\mathrm{Tr}$ & $\mathrm{Ro}$ & Activity & $N$ & $n$ \\
\hline $\mathrm{A}_{\mathrm{g}}$ & 1 & 1 & 1 & 1 & & & $\mathrm{R}$ & 4 & 4 \\
$\mathrm{~B}_{\mathrm{g}}$ & 1 & -1 & 1 & -1 & & $\mathrm{R}_{\mathrm{z}}$ & $\mathrm{R}$ & 2 & 1 \\
$\mathbf{A}_{\mathrm{u}}$ & 1 & 1 & -1 & -1 & $\mathrm{~T}_{\mathrm{y}}$ & & $\mathrm{IR}$ & 2 & 1 \\
$\mathbf{B}_{\mathrm{u}}$ & 1 & -1 & -1 & 1 & $\mathrm{~T}_{\mathrm{x}} \mathrm{T}_{\mathrm{z}}$ & & $\mathrm{IR}$ & 4 & 2 \\
\hline
\end{tabular}

a $N$ and $n$ denote the number of normal modes and of internal vibrations, respectively.

Table II. The character table for the point group $D_{2 h}$, symmetry species, selection rules, and number of normal modes for model $\mathrm{B}, \mathrm{C}, \mathrm{D}$, and $\mathrm{E}^{\mathrm{a}}$

\begin{tabular}{|c|c|c|c|c|c|c|c|c|c|c|c|c|c|c|c|}
\hline \multirow[t]{2}{*}{$D_{2 h}$} & \multirow[t]{2}{*}{$\mathrm{E}$} & \multirow[t]{2}{*}{$\mathrm{C}_{2} \mathrm{~S}(\mathrm{z})$} & \multirow[t]{2}{*}{$\mathrm{C}_{2}(\mathrm{y})$} & \multirow[t]{2}{*}{$\mathrm{C}_{2}(\mathrm{x})$} & \multirow[t]{2}{*}{$\mathrm{i}$} & \multirow[t]{2}{*}{$\sigma(\mathrm{xy})$} & \multirow[t]{2}{*}{$\sigma(\mathbf{z x})$} & \multirow[t]{2}{*}{$\sigma_{\mathrm{g}}(\mathrm{yz})$} & \multirow[t]{2}{*}{$\operatorname{Tr}$} & \multirow[t]{2}{*}{ Ro } & \multirow{2}{*}{ Activity } & \multicolumn{2}{|c|}{ for model $B$} & \multicolumn{2}{|c|}{$\begin{array}{c}\text { for model } \\
\mathrm{C}, \mathrm{D}, \text { and } \mathrm{E}\end{array}$} \\
\hline & & & & & & & & & & & & $N$ & $n$ & $N$ & $n$ \\
\hline $\mathrm{A}_{\mathrm{g}}$ & 1 & 1 & 1 & 1 & 1 & 1 & 1 & 1 & & & $\mathbf{R}$ & 2 & 2 & 4 & 4 \\
\hline $\mathbf{B}_{1 \mathrm{~g}}$ & 1 & 1 & -1 & -1 & 1 & 1 & -1 & -1 & & $\mathbf{R}_{\mathrm{z}}$ & $\mathrm{R}$ & 2 & 1 & 2 & 1 \\
\hline $\mathbf{B}_{2 \mathrm{~g}}$ & 1 & -1 & 1 & -1 & 1 & -1 & 1 & -1 & & & $\mathrm{R}$ & 2 & 2 & 4 & 4 \\
\hline$B_{3 g}$ & 1 & -1 & -1 & 1 & 1 & -1 & -1 & 1 & & & $\mathbf{R}$ & 0 & 0 & 2 & 2 \\
\hline $\mathbf{A}_{\mathrm{u}}$ & 1 & 1 & 1 & 1 & -1 & -1 & -1 & -1 & & & & 0 & 0 & 2 & 2 \\
\hline $\mathbf{B}_{1 \mathrm{u}}$ & 1 & 1 & -1 & -1 & -1 & -1 & 1 & 1 & $\mathbf{T}_{\mathrm{z}}$ & & IR & 2 & 1 & 4 & 3 \\
\hline $\mathbf{B}_{2 \mathrm{u}}$ & 1 & -1 & 1 & -1 & -1 & 1 & -1 & 1 & $\mathrm{~T}_{\mathrm{y}}$ & & IR & 2 & 1 & 2 & 1 \\
\hline $\mathbf{B}_{3 \mathrm{u}}$ & 1 & -1 & -1 & 1 & -1 & 1 & 1 & -1 & $T_{x}$ & & IR & 2 & 1 & 4 & 3 \\
\hline
\end{tabular}

a $N$ and $n$ denote the number of normal modes and of internal vibrations, respectively. 


\section{H. Shirakawa and S. Ikeda}

In the model structure A and B one chemical unit of acetylene is contained in the repeating unit, and in the model structure $\mathrm{C}, \mathrm{D}$, and $\mathrm{E}$ two chemical units of acetylene. The symmetry elements and unit cells of these models are illustrated in Figure $2 a$ and $2 b$, where the screw axis is denoted by $\mathrm{Cs}^{\mathrm{s}}$ and the glide plane by $\sigma_{\mathrm{g}}$.

The normal modes may be treated under the factor groups isomorphous to the point group $\mathrm{C}_{2 \mathrm{~h}}$ for model $\mathrm{A}$, and to the point group $\mathrm{D}_{2 \mathrm{~h}}$ for models B, C, D, and E. The character tables for the point group $C_{2 h}$ and $D_{2 h}$ are given in Table I and II, respectively. The number of normal modes $(N)$ and of internal vibrations $(n)$ and selection rules in the infrared (IR) and Raman (R) spectra under each symmetry species derived from the factor group analysis are also shown in Table I for model A and in Table II for models B, C, D, and E.

Notations expressing the bond lengths and the bond angles are given in Figure 3. As internal
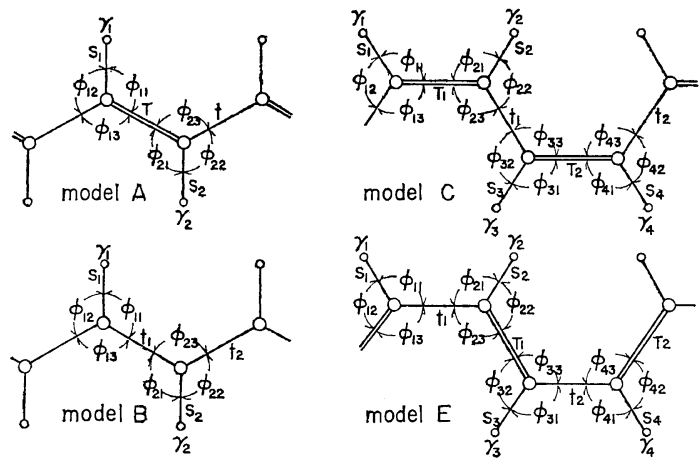

Figure 3. Internal coordinates for model structures. The same sets of coordinates as model $\mathrm{C}$ were assumed for model $\mathbf{D}$. coordinates we have selected the following: $\mathrm{C}-\mathrm{H}$ bond stretching $(\Delta s), \mathrm{C}-\mathrm{C}$ bond stretching $(\Delta T$ and $\Delta t), \quad$ C-C-C deformation $\left(\Delta \alpha, \Delta \alpha_{i}=\right.$ $\left.1 / \sqrt{6}\left(2 \Delta \phi_{i 3}-\Delta \phi_{i 1}-\Delta \phi_{i 2}\right)\right)$, C-C-H deformation between the $\mathrm{C}-\mathrm{H}$ bond and the bisector of the C-C-C angle $\phi_{i 3}\left(\Delta \beta, \Delta \beta_{i}=1 / \sqrt{2}\left(\Delta \phi_{i 1}-\Delta \phi_{i 2}\right)\right)$, and deformation of the $\mathrm{C}-\mathrm{H}$ bond out of the plane of the adjacent C-C-C linkage $(\Delta \gamma)$. The torsion coordinate around the $\mathrm{C}-\mathrm{C}$ bond is omitted because the factor group modes do not include any C-C torsional vibrations in the infinite planer molecules. The normalized internal symmetry coordinates for infrared active vibrations are given in Table III. The result of the analysis indicates that the three fundamentals for trans models A and B are one C-H stretching, one $\mathrm{C}-\mathrm{H}$ in-plane deformation, and one $\mathrm{C}-\mathrm{H}$ out-of-plane deformation and the seven fundamentals for cis models including model $\mathrm{E}$ are two $\mathrm{C}-\mathrm{H}$ stretching, two $\mathrm{C}-\mathrm{H}$ in-plane deformation, one $\mathrm{C}-\mathrm{C}$ stretching, one $\mathrm{C}-\mathrm{H}$ out-ofplane deformation, and one C-C-C deformation.

\section{ASSIGNMENTS AND DISCUSSION}

Infrared spectra of poly(acetylene) and poly(acetylene- $d_{2}$ ) are shown in Figures 4 and 5, respectively. From the spectra, it can be seen that relative intensities of almost all bands observed vary with the polymerization temperature. Thus, relative intensities of 3013, 1292, and 1015 $\mathrm{cm}^{-1}$ bands increase with increasing the polymerization temperature. Intensity of the 1292 $\mathrm{cm}^{-1}$ band, however, was very weak in the polymer prepared at $150^{\circ} \mathrm{C}$. Corresponding bands in the spectrum of poly (acetylene- $d_{2}$ ) are found at 2231,916 , and $752 \mathrm{~cm}^{-1}$, respectively. Fre-

Table III. The normalized internal symmetry coordinates for infrared active vibration ${ }^{\mathrm{a}}$

\begin{tabular}{clllll}
\hline Model A & Model B & & Model C and D & \multicolumn{1}{c}{ Model E } \\
\hline $\mathbf{B}_{\mathrm{u}}$ & $\mathbf{B}_{1 \mathrm{u}}$ & $1 / \sqrt{2}\left(\Delta \beta_{1}-\Delta \beta_{2}\right)$ & $\mathrm{B}_{1 \mathrm{u}}$ & $1 / 2\left(\Delta \beta_{1}-\Delta \beta_{2}+\Delta \beta_{3}-\Delta \beta_{4}\right)$ & $1 / 2\left(\Delta \beta_{1}-\Delta \beta_{2}+\Delta \beta_{3}-\Delta \beta_{4}\right)$ \\
& & & & $1 / 2\left(\Delta \alpha_{1}-\Delta \alpha_{2}+\Delta \alpha_{3}-\Delta \alpha_{4}\right)$ & $1 / 2\left(\Delta \alpha_{1}-\Delta \alpha_{2}+\Delta \alpha_{3}-\Delta \alpha_{4}\right)$ \\
& & & & $1 / 2\left(\Delta s_{1}-\Delta s_{2}+\Delta s_{3}-\Delta s_{4}\right)$ & $1 / 2\left(\Delta s_{1}-\Delta s_{2}+\Delta s_{3}-\Delta s_{4}\right)$ \\
$\mathbf{A}_{\mathrm{u}}$ & $\mathrm{B}_{2 \mathrm{u}}$ & $1 / \sqrt{2}\left(\Delta \gamma_{1}+\Delta \gamma_{2}\right)$ & $\mathrm{B}_{2 \mathrm{u}}$ & $1 / 2\left(\Delta \gamma_{1}+\Delta \gamma_{2}+\Delta \gamma_{3}+\Delta \gamma_{4}\right)$ & $1 / 2\left(\Delta \gamma_{1}+\Delta \gamma_{2}+\Delta \gamma_{3}+\Delta \gamma_{4}\right)$ \\
$\mathbf{B}_{\mathrm{u}}$ & $\mathrm{B}_{3 \mathrm{u}}$ & $1 / \sqrt{2}\left(\Delta s_{1}-\Delta s_{2}\right)$ & $\mathrm{B}_{3 \mathrm{u}}$ & $1 / 2\left(\Delta s_{1}+\Delta s_{2}-\Delta s_{3}-\Delta s_{4}\right)$ & $1 / 2\left(\Delta s_{1}+\Delta s_{2}-\Delta s_{3}-\Delta s_{4}\right)$ \\
& & & & $1 / \sqrt{2}\left(\Delta T_{1}-\Delta T_{2}\right)$ & $1 / \sqrt{2}\left(\Delta t_{1}-\Delta t_{2}\right)$ \\
& & & & $1 / 2\left(\Delta \beta_{1}+\Delta \beta_{2}-\Delta \beta_{3}-\Delta \beta_{4}\right)$ & $1 / 2\left(\Delta \beta_{1}+\Delta \beta_{2}-\Delta \beta_{3}-\Delta \beta_{4}\right)$ \\
\hline
\end{tabular}

a Here $\alpha_{i}=1 / \sqrt{6}\left(2 \Delta \phi_{i 3}-\Delta \phi_{i 1}-\Delta \phi_{i 2}\right)$ and $\beta_{i}=1 / \sqrt{2}\left(\Delta \phi_{i 1}-\Delta \phi_{i 2}\right)$. 
Infrared Spectra of Poly(acetylene)

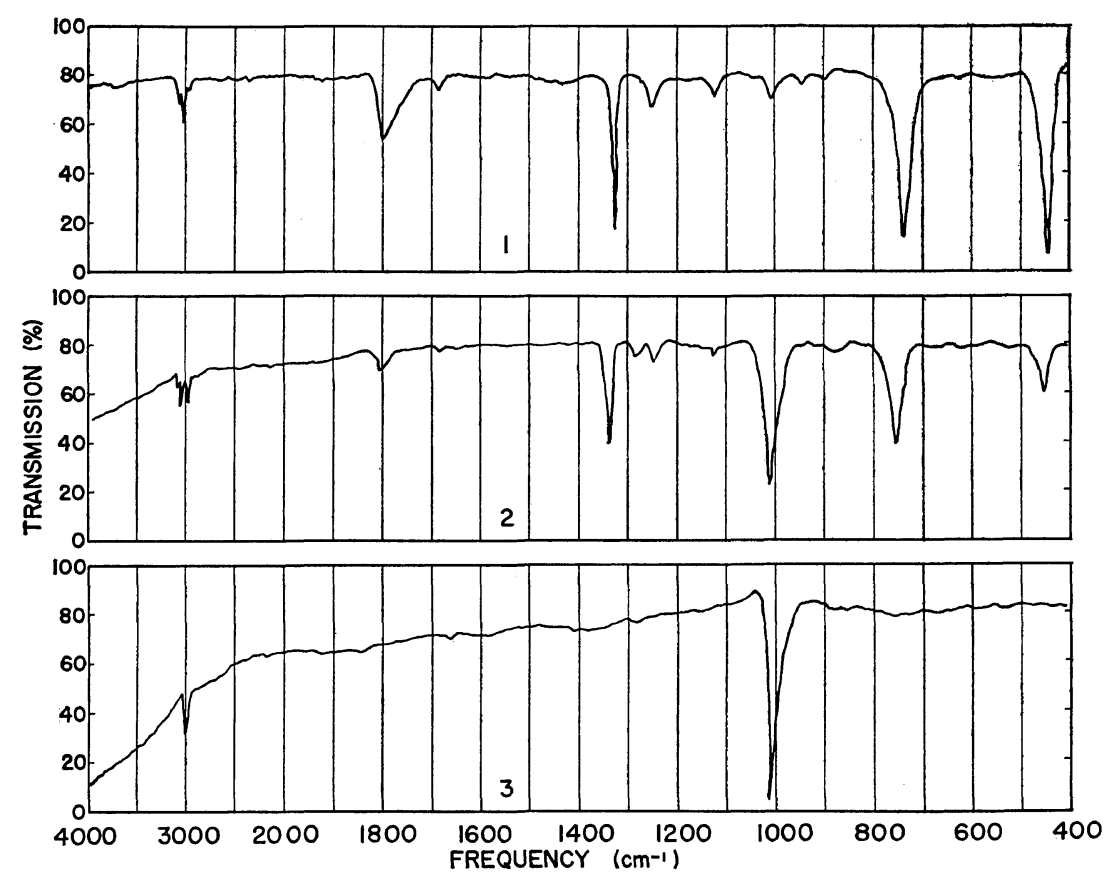

Figure 4. Infrared spectra of poly(acetylene) prepared at $(1)-78^{\circ} \mathrm{C},(2) 20^{\circ} \mathrm{C}$, and (3) $150^{\circ} \mathrm{C}$.

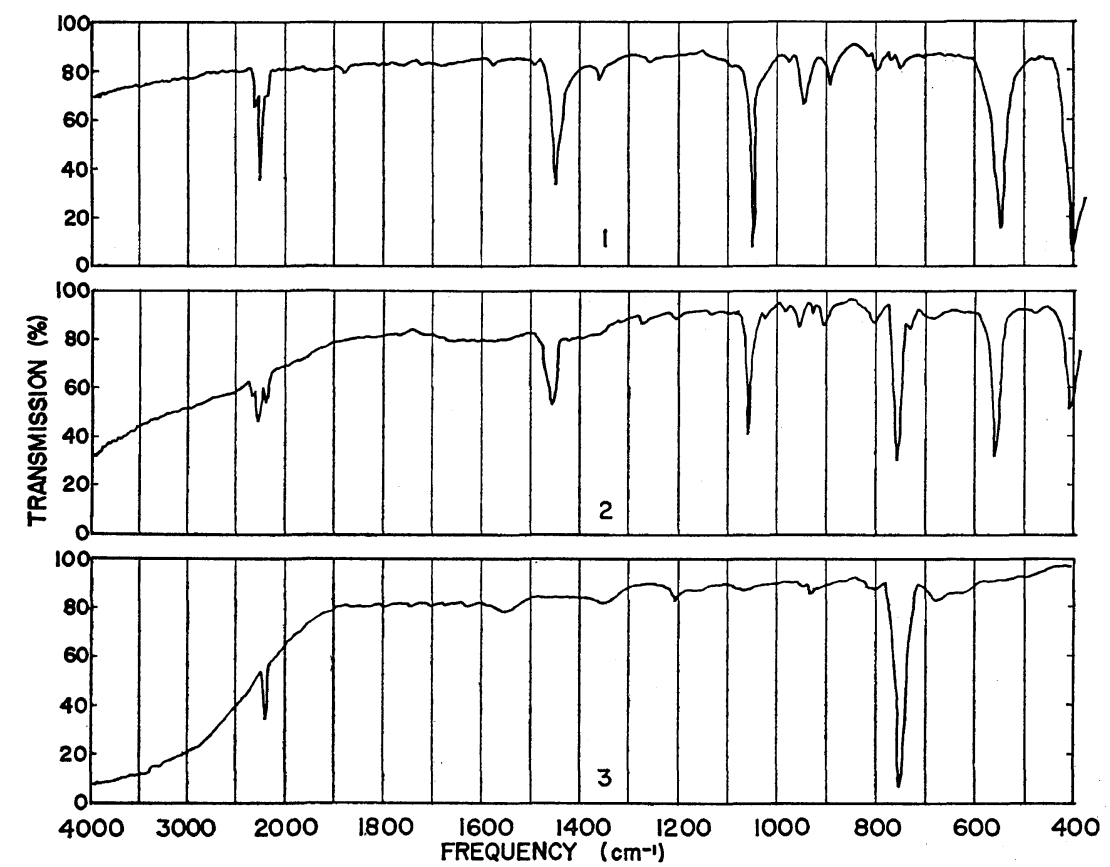

Figure 5. Infrared spectra of poly (acetylene- $d_{2}$ ) prepared at (1) $-78^{\circ} \mathrm{C}$, (2) $24^{\circ} \mathrm{C}$, and (3) $150^{\circ} \mathrm{C}$. 
quency ratios of these bands $\left(\nu_{\mathrm{H}} / \nu_{\mathrm{D}}\right)$ are 1.35, 1.41 , and 1.35 , respectively, which are nearly the same as the factor $\sqrt{13 / 7}=1.363$ calculated from the relative masses of thehy drogen, deuterium, and carbon atoms. This indicates that these bands may be assigned to $\mathrm{C}-\mathrm{H}$ stretching or $\mathrm{C}-\mathrm{H}$ deformation modes.

The out-of-plane deformation vibrations of hydrogen attached to trans $\mathrm{C}-\mathrm{C}$ double bonds in various ethylenic compounds are usually observed in the vicinity of $980-960 \mathrm{~cm}^{-1}$. Conjugation of tsans double bonds increases the band frequency. Lunde, et al., ${ }^{5}$ have shown that the C-H out-of-plane deformation bands appear at $960 \mathrm{~cm}^{-1}$ in trans-stilbene, $985 \mathrm{~cm}^{-1}$ in trans, trans-1,4-diphenylbutadiene-1,3, $994 \mathrm{~cm}^{-1}$ in alltrans-1,6-diphenylhexatriene-1,3,5, and $1010 \mathrm{~cm}^{-1}$ in all-trans-1,8-diphenyloctateraene-1,3,5,7. On this basis, the $1015 \mathrm{~cm}^{-1}$ band is reasonably assigned to the trans out-of-plane hydrogen deformation in trans configuration along the chains. According to Bellamy, ${ }^{6}$ the trans $\mathrm{C}-\mathrm{H}$ in-plane deformation should occur between 1310-1295 $\mathrm{cm}^{-1}$. Therefore, the band at $1292 \mathrm{~cm}^{-1}$ is assigned to the trans $\mathrm{C}-\mathrm{H}$ in-plane deformation. The band at $3013 \mathrm{~cm}^{-1}$ should be assigned to $\mathrm{C}-\mathrm{H}$ stretching in trans configuration. These assignments are consistent with the result expected from the consideration of both trans models (A and $\mathrm{B}$ ).

Relative intensities of $3057,3044,1329,1249$, 740 , and $446 \mathrm{~cm}^{-1}$ bands in poly(acetylene) and corresponding bands at 2275, 2255, 1050, 947, 548 , and $402 \mathrm{~cm}^{-1}$ in poly (acetylene- $d_{2}$ ) increase by decreasing the polymerization temperature. Respective frequency ratios of poly(acetylene) to poly $\left(\right.$ acetylene- $\left.d_{2}\right)$ are $1.34,1.35,1.27,1.32,1.35$, and 1.11. From the ratio of 1.11 , the $446 \mathrm{~cm}^{-1}$ band is clearly such a vibration as no hydrogen atoms are concerned. It is, therefore, concluded that the band is assigned to the $\mathrm{B}_{1 \mathrm{u}} \mathrm{C}-\mathrm{C}-\mathrm{C}$ deformation in cis configuration. In the $\mathrm{C}-\mathrm{H}$ deformation frequency region, Lunde, et al., ${ }^{5}$ have shown that the spectrum of cis isomer of various diphenylpolyenes contain two bands absent from all trans spectra. One is the weak to moderate band assigned to in-plane vibrations of hydrogen attached to cis $\mathrm{C}-\mathrm{C}$ double bonds located at roughly the same wave number, 1430 $-1410 \mathrm{~cm}^{-1}$, but in the spectrum of cis, cis-1,4- diphenylbutadiene-1,3 the band is shifted to $1368 \mathrm{~cm}^{-1}$. The other band is assigned to outof-plane vibrations of hydrogen attached to cis C-C double bonds which appear at $779-772 \mathrm{~cm}^{-1}$. Hwa, et al. ${ }^{11}$ have shown that the cis out-ofplane deformation band of cis-hexatriene-1,3,5 appears at $818 \mathrm{~cm}^{-1}$ by comparison with the spectrum of the trans isomer. The two bands at 1329 and $1249 \mathrm{~cm}^{-1}$, on this basis, may be assigned to cis $\mathrm{C}-\mathrm{H}$ in-plane deformation of $\mathrm{B}_{1 \mathrm{u}}$ and $B_{3 \mathrm{u}}$ modes predicted from the analysis of cis-transoid (or trans-cisoid) skeleton models. The band at $740 \mathrm{~cm}^{-1}$ is assigned to cis $\mathrm{C}-\mathrm{H}$ out-of-plane deformation. The bands at 3057 and $3044 \mathrm{~cm}^{-1}$ are assigned to the $B_{1 u}$ and $B_{3 u} C-H$ stretching vibrations which are also predicted from the analysis.

It was not possible to identify which band is the $\mathrm{B}_{1 \mathrm{u}}$ or $\mathrm{B}_{3 \mathrm{u}}$ mode in the two $\mathrm{C}-\mathrm{H}$ stretching bands as well as in the two $\mathrm{C}-\mathrm{H}$ in-plane deformation bands, because well stretched film to obtain the polarized spectra could not be prepared. The 3057 and $1329 \mathrm{~cm}^{-1}$ bands, however, are tentatively assigned to the $\mathrm{B}_{1 \mathrm{u}}$ mode and 3044 and $1249 \mathrm{~cm}^{-1}$ bands to the $B_{3 u}$ mode, the observed ratio of product rule for $B_{1 u}$ is 1.89 being nearly the same as the calculated ratio $2 \sqrt{13 / 14}=1.927$. For the $B_{3 u}$ mode the observed ratio of product rule could not be obtained, because there is no unambiguous band of carbon - carbon stretching mode in the spectra of poly(acetylene) and poly (acetylene- $d_{2}$ ).

Bellamy ${ }^{6}$ lists the range of $1680-1620 \mathrm{~cm}^{-1}$ for the C-C double bond stretching vibration with a conjugated system, the frequency being lowered toward $1600 \mathrm{~cm}^{-1}$. The C-C single bond stretching occurs between $1200-1000 \mathrm{~cm}^{-1}$. Conjugation increases the single bond frequency. Analysis of the normal vibrational modes in the cis-transoid (or trans-cisoid structure indicates that stretching of the C-C double bond or shorter bond should be infrared active mode in cis-transoid structure (Figure 1C), whereas the C-C single bond or longer bond stretching vibration should be active in the trans-cisoid structure (Figure $1 \mathrm{E})$. Thus it is expected that a band will appear in the vicinity of $1600 \mathrm{~cm}^{-1}$ in the case of cistransoid structure and in the range of 1200-1000 $\mathrm{cm}^{-1}$ in trans-cisoid structure. In the case of $\mathrm{D}$ structure in which all carbon-carbon bonds 
are equal in length and may have intermediate character between single and double bonds, the stretching vibration of the $\mathrm{C}-\mathrm{C}$ bonds should appear in the vicinity of $1400 \mathrm{~cm}^{-1}$.

As shown in Figure 4, there is no such band either in the vicinity of $1600 \mathrm{~cm}^{-1}$ or $1400 \mathrm{~cm}^{-1}$. A band at $1118 \mathrm{~cm}^{-1}$ in the spectra of poly(acetylene) prepared at low temperature decreases its relative intensity with increasing the polymerization temperature, and is concerned with cis-transoid (or trans-cisoid) structures. On this basis, the band may be assigned to the carbon-carbon stretching vibration of transcisoid structure. In the spectra of poly(acetylene$d_{2}$ ), however, corresponding bands could not be found in the region of $1000-1100 \mathrm{~cm}^{-1}$ expected from small isotope shift.

On standing in air at room temperature, poly(acetylene) prepared by the $\mathrm{Ti}\left(\mathrm{OC}_{4} \mathrm{H}_{9}\right)-\mathrm{Al}\left(\mathrm{C}_{2} \mathrm{H}_{5}\right)_{3}$ system reacts slowly with oxygen to give an oxygenated material which is characterized in the infrared spectrum by the presence of a strong band at $1670 \mathrm{~cm}^{-1}$ and a medium band at 1720 $\mathrm{cm}^{-1}$ due to the stretching vibrations of carbonyl groups. Higashiura, et al. ${ }^{17}$ have tentatively assigned the bands at 1680 and $1720 \mathrm{~cm}^{-1}$ in the oxygenated poly(acetylene) to the stretching vibrations of carbonyl groups of $\alpha, \beta$-unsaturated ketone and $\alpha$-diketone, respectively. We have also observed a relatively strong band at 1800 $\mathrm{cm}^{-1}$ in fresh polymers. The band may be due to the cis configuration since its intensity increases by decreasing the polymerization temperature.

Bellamy ${ }^{6}$ describes overtones of $\mathrm{CH}_{2}$ wagging which appear in the range of $1750-1800$ and of $1800-1850 \mathrm{~cm}^{-1}$ in the compounds of the type $\mathrm{RR}^{\prime} \mathrm{C}=\mathrm{CH}_{2}$ and $\mathrm{RCH}=\mathrm{CH}_{2}$, respectively. A band in the vicinity of $1800 \mathrm{~cm}^{-1}$ has also been reported in $1,3,5$-hexatriene, ${ }^{10 a, 11} 1,3,5,7$-octatetraene, ${ }^{10 b, 18} 1,3,5,7,9$-decapentaene $,{ }^{19,20} 1,3,5,7$, 9,11-dodecahexaene, ${ }^{19}$ and $1,3,5,7,9,11,13,15$ hexadecaoctaene. ${ }^{19}$ Lippincott, et al., have assigned a strong band at $1810 \mathrm{~cm}^{-1}$ and a medium band at $1750 \mathrm{~cm}^{-1}$ in trans-1,3,5-hexatriene $\mathrm{e}^{10 \mathrm{a}}$ and three bands at $1889(\mathrm{w}), 1802(\mathrm{~s})$, and $1764 \mathrm{~cm}^{-1}$ (w) in trans, trans-1,3,5,7-octatetraen $\mathrm{e}^{10 \mathrm{~b}}$ to combination bands. These observations suggest that

Table IV. Assignments of the infrared spectra of poly(acetylene) and poly(acetylene- $\left.d_{2}\right)$

\begin{tabular}{|c|c|c|c|c|c|c|c|c|c|}
\hline \multicolumn{8}{|c|}{ Observed frequency $\left(\mathrm{cm}^{-1}\right)$ and intensity } & \multirow{2}{*}{\multicolumn{2}{|c|}{ Assignment }} \\
\hline \multicolumn{4}{|c|}{ poly(acetylene) } & \multicolumn{4}{|c|}{ poly (acetylene- $\left.d_{2}\right)$} & & \\
\hline 3057 & $\mathrm{vw}^{\mathrm{a}}$ & $v w^{b}$ & $-\mathrm{d}$ & 2275 & $\mathrm{vw}^{\mathrm{a}}$ & $\mathrm{vw}^{\mathrm{c}}$ & $一^{\mathrm{d}}$ & $\mathrm{B}_{1 \mathrm{u}}$ & $\mathrm{C}-\mathrm{H}$ stretching in $c i s$ \\
\hline 3044 & $\mathrm{w}$ & $\mathrm{w}$ & - & 2255 & $\mathrm{~m}$ & w & - & $\mathbf{B}_{3 \mathrm{u}}$ & $\mathrm{C}-\mathrm{H}$ stretching in cis \\
\hline 3013 & vvw & $\mathrm{w}$ & $\mathrm{m}$ & 2231 & $\mathrm{w}$ & $\mathrm{w}$ & $\mathrm{m}$ & $\mathrm{B}_{3 \mathrm{u}}$ & $\mathrm{C}-\mathrm{H}$ stretching in trans \\
\hline \multirow[t]{2}{*}{1800} & $\mathrm{~m}$ & $\mathrm{w}$ & - & & & & & & $1329+446=1785 ?$ \\
\hline & & & & 1448 & $\mathrm{~s}$ & $\mathrm{~m}$ & - & & $1050+402=1452 ?$ \\
\hline \multirow[t]{2}{*}{1690} & vw & vvw & - & & & & & & $1249+446=1695 ?$ \\
\hline & & & & 1360 & vw & - & - & & $947+402=1349 ?$ \\
\hline \multirow[t]{2}{*}{1329} & s & $\mathrm{m}$ & - & 1050 & s & $\mathrm{m}$ & - & $\mathrm{B}_{1 \mathrm{u}}$ & $\mathrm{C}-\mathrm{H}$ in-plane deformation in cis \\
\hline & & & & 975 & vvw & vvw & - & & \\
\hline 1292 & - & vw & vvw & 916 & - & vvw & vw & $\mathbf{B}_{1 u}$ & $\mathrm{C}-\mathrm{H}$ in-plane deformation in trans \\
\hline \multirow[t]{2}{*}{1249} & $\mathrm{w}$ & vw & - & 947 & $\mathrm{w}$ & vw & - & $\mathbf{B}_{3 \mathrm{u}}$ & $\mathrm{C}-\mathrm{H}$ in-plane deformation in cis \\
\hline & & & & 892 & w & vw & - & & \\
\hline \multirow[t]{2}{*}{1118} & vw & vvw & - & & & & & $\mathrm{B}_{3 \mathrm{u}}$ & $\mathrm{C}-\mathrm{C}$ stretching in cis? \\
\hline & & & & 800 & vw & vw & - & & \\
\hline 1015 & vw & $\mathrm{s}$ & vs & 752 & vvw & s & vs & $\mathbf{B}_{2 u}$ & $\mathrm{C}-\mathrm{H}$ out-of-plane deformation in trans \\
\hline 980 & vvw & - & - & 735 & vvw & vvw & - & & $\begin{array}{l}\text { in }-(\text { trans } \mathrm{CH}=\mathrm{CH})_{2-} \\
\text { bet ween }-(\text { cis } \mathrm{CH}=\mathrm{CH})_{n^{-}}\end{array}$ \\
\hline 940 & $\mathrm{vw}$ & - & - & 720 & vvw & - & - & & $\begin{array}{l}\text { in }-(\text { trans } \mathrm{CH}=\mathrm{CH})_{1^{-}} \\
\text {between }-(\text { cis } \mathrm{CH}=\mathbf{C H})_{n^{-}}\end{array}$ \\
\hline 740 & vs & s & - & 548 & vs & s & - & $\mathbf{B}_{2 \mathrm{~h}}$ & $\mathrm{C}-\mathrm{H}$ out-of-plane deformation in cis \\
\hline 446 & vs & $\mathrm{m}$ & - & 402 & vs & $\mathrm{s}$ & - & $\mathbf{B}_{1 \mathrm{u}}$ & $\mathrm{C}-\mathrm{C}-\mathrm{C}$ deformation in $\mathrm{cis}$ \\
\hline
\end{tabular}


the band at about $1800 \mathrm{~cm}^{-1}$ may be characteristic of vinyl groups or conjugated polyenes. Although such bands have been observed in all trans or trans rich polyenes except cis-1,3,5-hexatrene, ${ }^{11}$ we could find no such bands in trans poly(acetylene. We have tentatively assigned the band at $1800 \mathrm{~cm}^{-1}$ to combinations of C-C-C deformation and $\mathrm{C}-\mathrm{H}$ in-plane vibrations. Corresponding bands in poly (acetylene- $d_{2}$ ) are observed at 1448 and $1360 \mathrm{~cm}^{-1}$. The intensities of these "combination" bands are considerably greater than would be expected. Their origin is therefore not entirely clear. These assignments are summarized in Table IV.

The spectral data are best interpreted on the basis of all trans configuration for the polymers prepared at temperatures higher than $150^{\circ} \mathrm{C}$, and all cis-transoid (or all trans-cisoid) configura- tions for the polymers prepared at temperatures lower than $-78^{\circ} \mathrm{C}$. The polymers obtained at the temperature range of $-78-150^{\circ} \mathrm{C}$, contain both cis-transoid (or trans-cisoid) and trans configurations. The ratio of cis-transoid (or trans-cisoid) to trans configuration depends strongly upon the polymerization temperature. Whether carbon-carbon bonds of poly(acetylene) are equal in length or alternately long or short and whether configuration of poly(acetylene) is cis-transoid or trans-cisoid could not be made clear at the present time, because of ambiguous assignment of the $\mathrm{C}-\mathrm{C}$ stretching vibration.

According to factor group analysis, the $\mathrm{C}-\mathrm{H}$ out-of-plane vibrations in both cis-transoid (or trans-cisoid) and trans skeleton models belong to the $B_{2 u}$ or $A_{u}$ mode in which only one fundamental is contained in either $C_{2 h}$ and $D_{2 h}$ sym-<smiles>COC(C)OB(O)OC(O)OC(=O)O</smiles>

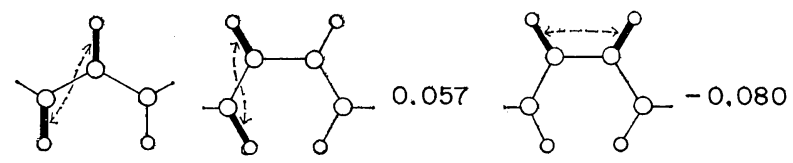

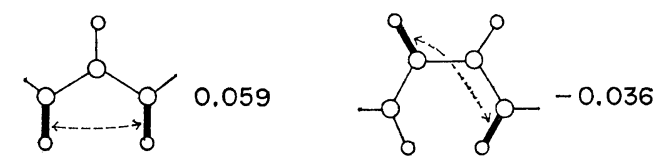<smiles>COC1OC2COC(O1)C(O)C(O)O2</smiles><smiles>COC1OC2COC(O1)C(O)C(O)O2</smiles>

Figure 6. Values of force constants for $\mathrm{C}$-H out-of-plane deformation (in md $\AA$ ). Interaction constants are shown by two coordinates connected with a broken line.

Table V. Calculated C-H and C-D out-of-plane deformation frequencies

\begin{tabular}{rrr}
\hline & \multicolumn{2}{c}{ Frequency, $\mathrm{cm}^{-1}$} \\
\cline { 2 - 3 } & Obsd & Calcd \\
\hline trans C-H & 1015 & 1014.8 \\
cis C-H & 740 & 740.5 \\
trans C-D & 752 & 745.2 \\
cis C-D & 548 & 543.7 \\
\hline
\end{tabular}

metry of model structures. If a suitable set of force constants for the C-H out-of-plane deformation mode is available, these frequencies can be easily calculated.

The calculations were carried out for B and D models in which all $\mathrm{C}-\mathrm{H}$ and $\mathrm{C}-\mathrm{C}$ bonds and all $\mathrm{C}-\mathrm{C}-\mathrm{H}$ and $\mathrm{C}-\mathrm{C}-\mathrm{C}$ angles were assumed to have common lengths ( 1.08 and $1.40 \AA)$ and a common angle $\left(120^{\circ}\right)$, respectively. Some force constants were estimated from $\mathrm{C}-\mathrm{H}$ out-of-plane frequencies 
in various $\alpha, \omega$-diphenylpolyenes under the same assumptions as those of poly(acetylene) models. A value of $0.427 \mathrm{md} \AA$ was obtained for $\mathrm{C}-\mathrm{H}$ out-of-plane deformation vibrations in both cis and trans configurations. Several interaction constants are schematically shown in Figure 6. Calculated and observed out-of-plane frequencies are listed in Table $\mathrm{V}$.

In the region of $\mathrm{C}-\mathrm{H}$ stretching, four very weak bands were observed at 2962,2931, 2875, and $2853 \mathrm{~cm}^{-1}$. These bands may be assigned to $\mathrm{CH}_{3}$ asymmetric, $\mathrm{CH}_{2}$ asymmetric, $\mathrm{CH}_{3}$ symmetric, and $\mathrm{CH}_{2}$ symmetric stretching, respectively, thus indicating the presence of the ethyl groups from the catalyst in the polymer chains. At the initiation step, acetylene molecules may be inserted between the metal-ethyl bond giving rise to incorporation of the ethyl group at the end of the growing chain.

In previous publications ${ }^{15,16}$ we have reported that benzoic acid was identified from the permanganate oxidation products of poly(acetylene) prepared with the systems of $\mathrm{TiCl}_{4}-\mathrm{Al}\left(\mathrm{C}_{2} \mathrm{H}_{5}\right)_{3}$ and $\operatorname{Ti}\left(\mathrm{OC}_{4} \mathrm{H}_{9}\right)_{4}-\mathrm{Al}\left(\mathrm{C}_{2} \mathrm{H}_{5}\right)_{3}$, and that the formation of benzoic acid is attributed to phenyl groups formed by terminal cyclization of growing chains. No evidence of phenyl groups, however, was obtained from infrared spectra.

\section{INFRARED SPECTRA OF COPOLY(ACE- TYLENE+ACETYLENE- $d_{2}$ ) AND COPOLY(ACETYLENE+ ACETYLENE- $d_{1}+$ ACETYLENE- $\left.d_{2}\right)$}

The infrared spectra of copoly (acetylene + acetylene- $d_{2}$ ) and copoly (acetylene + acetylene- $d_{1}+$ acetylene- $d_{2}$ ) show differences from superimposed spectra of poly(acetylene) and poly(acetylene- $d_{2}$ ) especially in the region of C-H and C-D out-ofplane deformation vibrations. The $\mathrm{C}-\mathrm{H}$ and C-D out-of-plane deformation bands shift to lower frequency in trans configuration whereas to higher frequency in cis-transoid or trans-cisoid configuration and split into several bands. Thus, the trans $\mathrm{C}-\mathrm{H}$ deformation vibrations appear between $1015-930 \mathrm{~cm}^{-1}$, the trans C-D bands $745-715 \mathrm{~cm}^{-1}$, the cis $\mathrm{C}-\mathrm{H}$ bands $810-743 \mathrm{~cm}^{-1}$, and the cis C-D bands $663-552 \mathrm{~cm}^{-1}$ in the case of copoly(acetylene + acetylene- $d_{2}$ ). Figures 7 and 8 show the spectra of all trans copolymers pre-

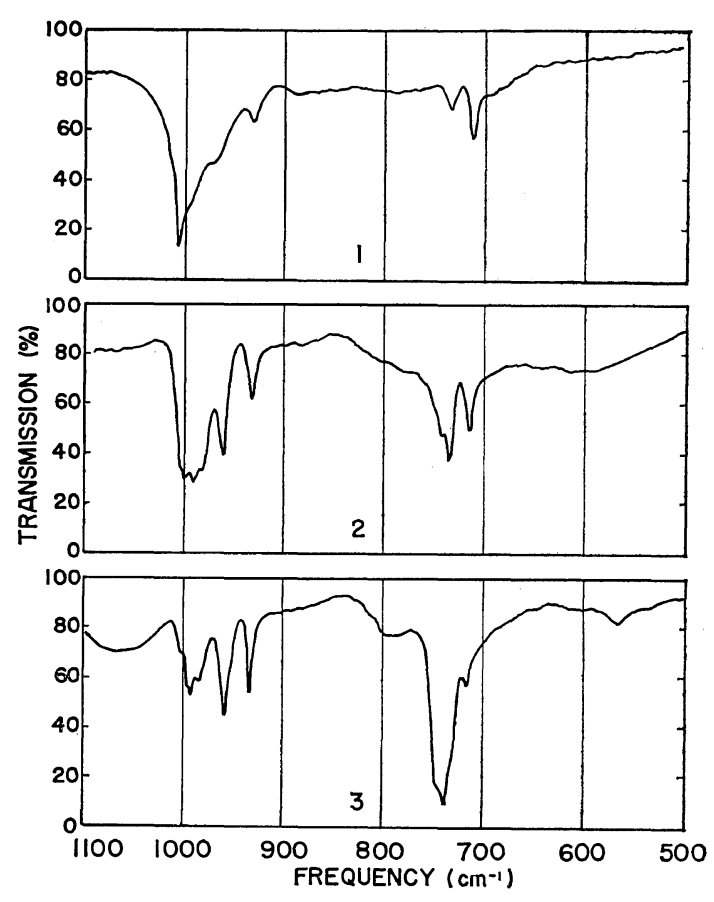

Figure 7. Infrared spectra of copoly(acetylene+ acetylene- $d_{2}$ ) prepared at $150^{\circ} \mathrm{C}: 1$, feed monomer ratio, $\mathrm{C}_{2} \mathrm{H}_{2} / \mathrm{C}_{2} \mathrm{D}_{2}=80 / 20 ; 2,50 / 50 ; 3,20 / 80$.

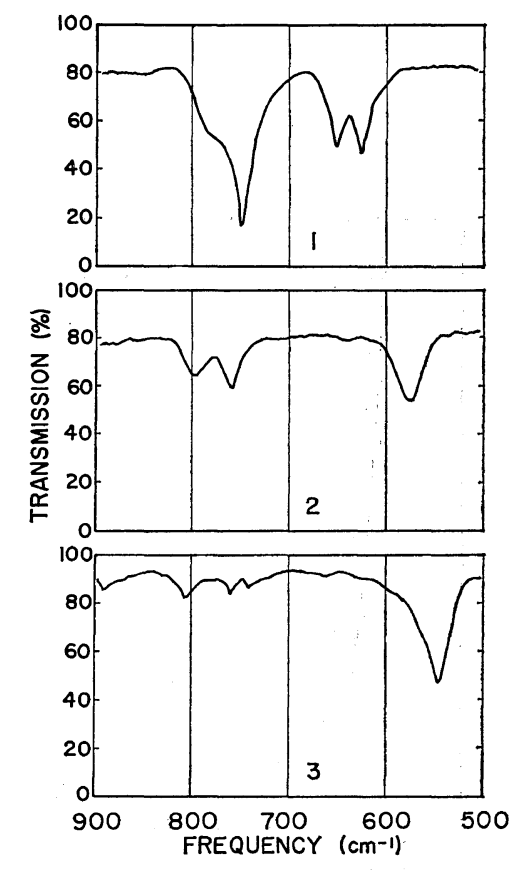

Figure 8. Infrared spectra of copoly(acetylene+ acetylene- $d_{2}$ ) prepared at $-78^{\circ} \mathrm{C}: \quad 1$, feed monomer ratio, $\mathrm{C}_{2} \mathrm{H}_{2} / \mathrm{C}_{2} \mathrm{D}_{2}=80 / 20 ; 2,50 / 50 ; 3,20 / 80$. 
pared at $150^{\circ} \mathrm{C}$ and of all cis-transoid (or all trans-cisoid) copolymers obtained at $-78^{\circ} \mathrm{C}$, respectively, in the region of $\mathrm{C}-\mathrm{H}$ and $\mathrm{C}-\mathrm{D}$ outof-plane deformation frequencies. As shown in the Figures, these shifts and splittings vary with the monomer ratio in the copolymers. Interaction between $\mathrm{C}-\mathrm{H}$ and C-D out-of-plane vibrations may give rise to the shifts and splittings in the copolymers.

Simplified calculations of C-H and C-D outof-plane deformation frequencies were made for various model chains having repeating units of $-\left(\mathrm{C}_{2} \mathrm{D}_{2}\right)_{m}-\left(\mathrm{C}_{2} \mathrm{H}_{2}\right)_{n}$ - in which both $n$ and $m$ were based on the in-phase mode of $-\left(\mathrm{C}_{2} \mathrm{D}_{2}\right)_{m^{-}}$and $-\left(\mathrm{C}_{2} \mathrm{H}_{2}\right)_{n}$ - using a set of force constants given in Figure 6, and carried out for three models: (1) all trans skeleton, (2) all cis-transoid (or all trans-cisoid) skeleton in which two adjacent hydrogen or deuterium atoms originated from an acetylene molecule are arranged in cis configuration (cis I), and (3) in trans configuration (cis II). Examples for each model in the case of $m=1$ and $n=1$ are illustrated in Figure 9, where only skeletons are shown. The calculated results are shown in Figure 10 for the trans model, in Figure 11 for the cis I model, and in Figure 12 for the cis II model.

In a comparison of the calculated result of the trans model with spectra of the copoly(acetylene +acetylene- $d_{2}$ ) prepared at $150^{\circ} \mathrm{C}$, the bands at 932, 964, 983, and $990 \mathrm{~cm}^{-1}$ may be assigned to the trans $\mathrm{C}-\mathrm{H}$ out-of-plane deformations in $-(\mathrm{CH}=\mathrm{CH})_{n^{-}}$between $-(\mathrm{CD}=\mathrm{CD})_{m^{-}} \quad m \geq 1$, where $n=1,2,3$, and 4 , respectively, and the bands at 715 and $735 \mathrm{~cm}^{-1}$ to the C-D out-ofplane deformations in $-(\mathrm{CD}=\mathrm{CD})_{1}-$ between $-(\mathrm{CH}=\mathrm{CH})_{1-2^{-}}$and $-(\mathrm{CD}=\mathrm{CD})_{2}-\quad$ between $-(\mathrm{CH}=\mathrm{CH})_{1-3^{-}}$, respectively. Comparison of the calculated result based upon the cis models with observed spectra in the copolymer prepared at

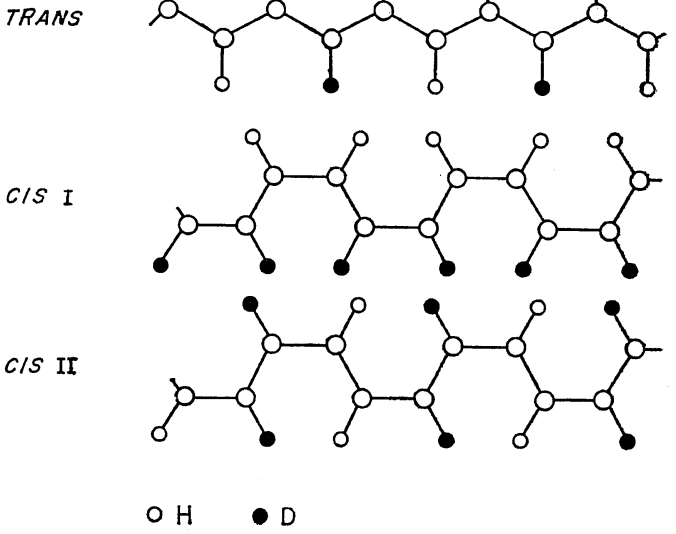

Figurre 9. Arrangement of $\mathrm{H}$ and $\mathrm{D}$ atoms along model chains in the case of $m=1$ and $n=1$.

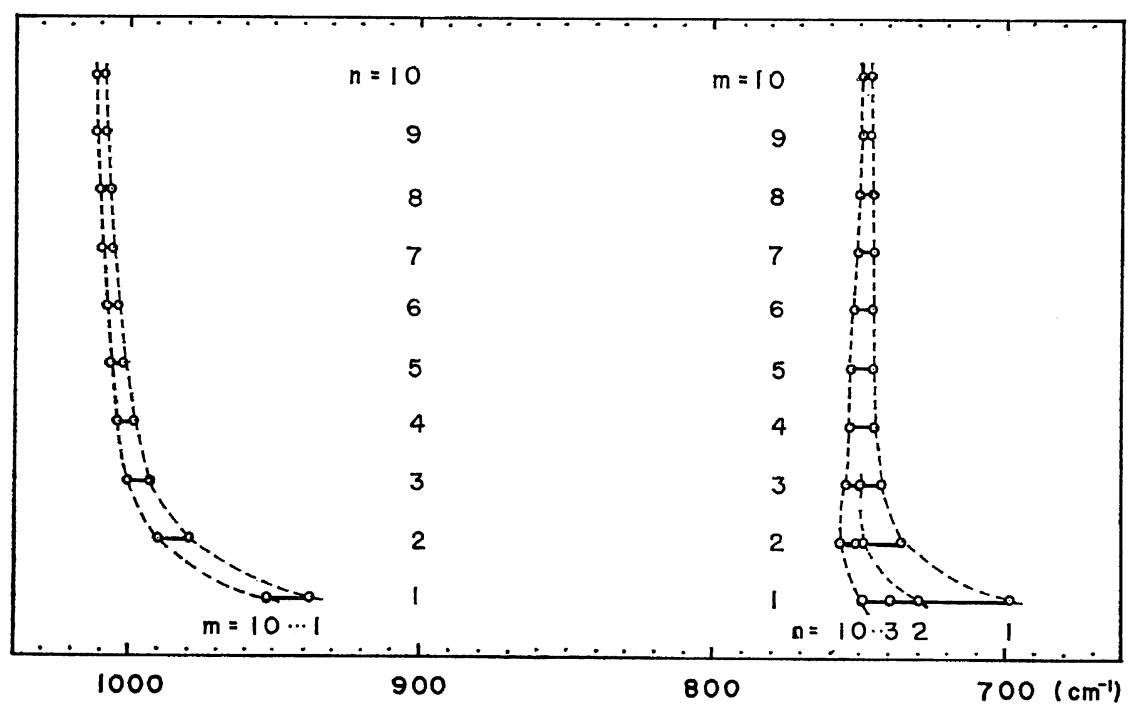

Figure 10. Locations of the calculated frequencies of C-H and C-D out-of-plane deformation modes in all trans model copolymers. Repeating unit is $-\left(\mathrm{C}_{2} \mathrm{D}_{2}\right)_{m}-\left(\mathrm{C}_{2} \mathrm{H}_{2}\right)_{n^{-}}$. 


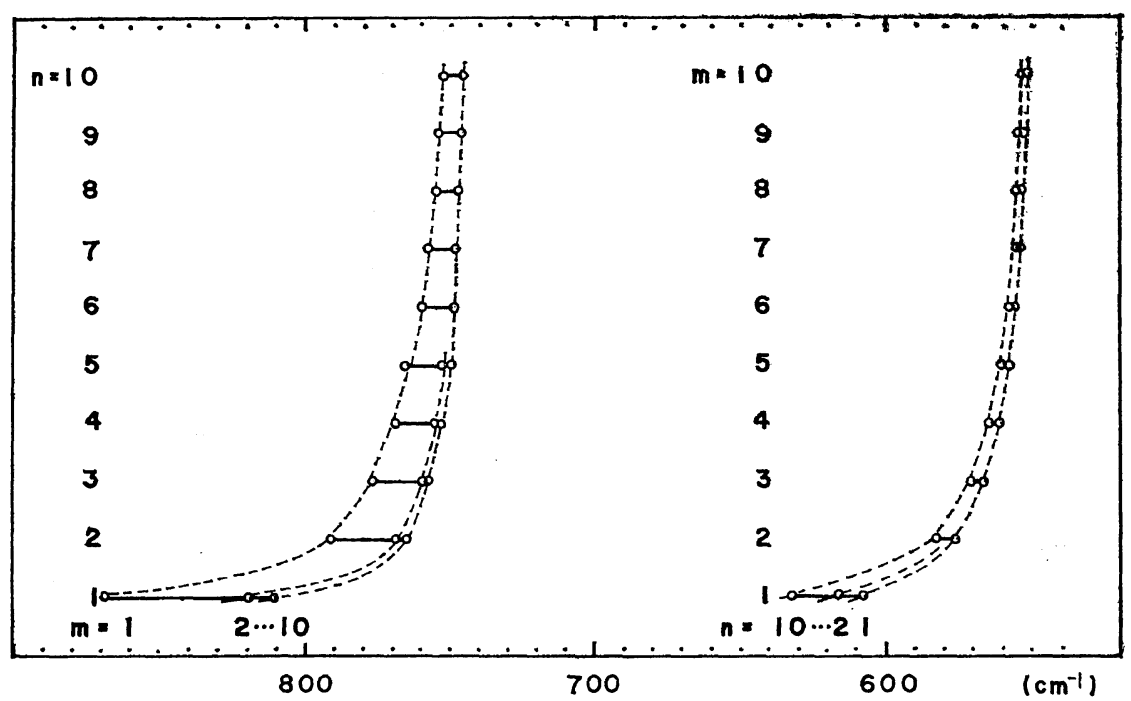

Figure 11. Locations of the calculated frequencies of $C-H$ and $C-D$ out-of-plane deformation modes in cis I type model copolymers. Repeating unit is $-\left(\mathrm{C}_{2} \mathrm{D}_{2}\right)_{m}-\left(\mathrm{C}_{2} \mathrm{H}_{2}\right)_{n^{-}}$.

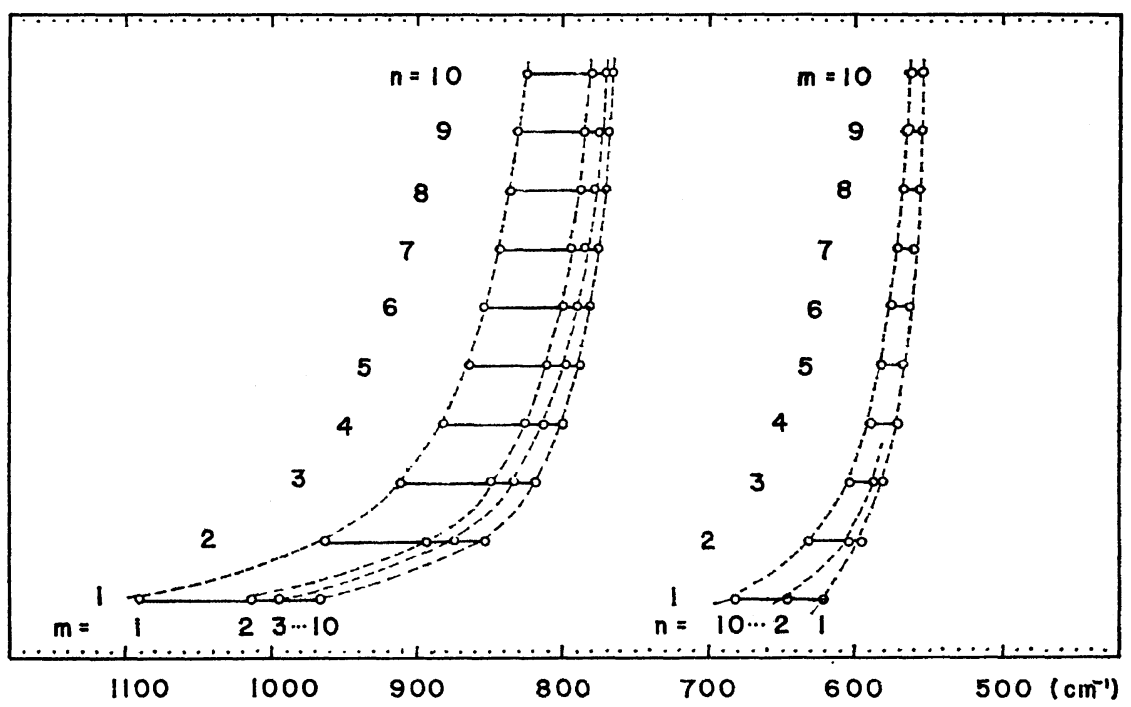

Figure 12. Locations of the calculated frequencies of C-H and C-D out-of-plane de formation modes in cis II type model copolymers. Repeating unit is $-\left(\mathrm{C}_{2} \mathrm{D}_{2}\right)_{m}-\left(\mathrm{C}_{2} \mathrm{H}_{2}\right)_{n^{-}}$.

$-78^{\circ} \mathrm{C}$ leads to the result that arrangement of hydrogen and deuterium atoms in the copolymer seems likely to have the same arrangement as in the cis I model. Thus, the bands at 810,800 , and $760 \mathrm{~cm}^{-1}$ may be assigned to the cis $\mathrm{C}-\mathrm{H}$ out-of-plane deformations in $-(\mathrm{CH}=\mathrm{CH})_{n^{-}}$, between $-(\mathrm{CD}=\mathrm{CD})_{m}-m \geq 1$, where $n=1,2$, and $3-5$, respectively. In these sequences two hy- drogen atoms as well as two deuterium atoms in a chemical unit of acetylene are in cis configuration. Corresponding frequencies calculated on the basis of the cis II model are about 1000, 880 , and $820 \mathrm{~cm}^{-1}$, respectively, which are too high to be assigned to the observed cis $\mathrm{C}-\mathrm{H}$ out-of-plane frequencies. The assignments are collected in Table VI. The copoly(acetylene + 


\section{H. Shirakawa and S. IKeda}

Table VI. Assignments of C-H and C-D out-of-plane deformation vibrations in copoly (acetylene + acetylene- $d_{2}$ )

\begin{tabular}{|c|c|c|c|}
\hline & Frequency, $\mathrm{cm}^{-1}$ & Assignment & \\
\hline & trans $\mathrm{C}-\mathrm{H}$ out-of-plane deformation & & \\
\hline 1000 & $-(\mathrm{CH}=\mathrm{CH})_{n^{-}} \quad n \geqq 5$ & between $-(\mathrm{CD}=\mathrm{CD})_{m^{-}}$ & $m \geqq 1$ \\
\hline 990 & $-(\mathrm{CH}=\mathrm{CH})_{4}-$ & between $-(\mathrm{CD}=\mathrm{CD})_{m^{-}}$ & $m \geqq 1$ \\
\hline 983 & $-(\mathrm{CH}=\mathrm{CH})_{3^{-}}$ & between $-(\mathrm{CD}=\mathrm{CD})_{m^{-}}$ & $m \geqq 1$ \\
\hline 964 & $-(\mathrm{CH}=\mathrm{CH})_{2^{-}}$ & between $-(\mathrm{CD}=\mathrm{CD})_{m^{-}}$ & $m \geqq 1$ \\
\hline 932 & $-(\mathrm{CH}=\mathrm{CH})_{1^{-}}$ & between $-(\mathrm{CD}=\mathrm{CD})_{m^{-}}$ & $m \geqq 1$ \\
\hline & trans C-D out-of-plane deformation & & \\
\hline 742 & $-(\mathrm{CD}=\mathrm{CD})_{m^{-}} \quad m \geqq 3$ & between $-(\mathrm{CH}=\mathrm{CH})_{n^{-}}$ & $n \geqq 1$ \\
\hline 735 & $-(\mathrm{CD}=\mathrm{CD})_{2^{-}}$ & between $-(\mathrm{CH}=\mathrm{CH})_{1-3^{-}}$ & \\
\hline 715 & $\begin{array}{c}-(\mathrm{CD}=\mathrm{CD})_{1^{-}} \\
\text {cis } \mathrm{C}-\mathrm{H} \text { out-of-plane deformation }\end{array}$ & between $-(\mathrm{CH}=\mathrm{CH})_{1-2^{-}}$ & \\
\hline 810 & $-(\mathrm{CH}=\mathrm{CH})_{1^{-}}$ & between $-(\mathrm{CD}=\mathrm{CD})_{m^{-}}$ & $m \geqq 1$ \\
\hline 800 & $-(\mathrm{CH}=\mathrm{CH})_{2-}$ & between $-(\mathrm{CD}=\mathrm{CD})_{m^{-}}$ & $m \geqq 1$ \\
\hline 760 & $-(\mathrm{CH}=\mathrm{CH})_{3-5^{-}}$ & between $-(\mathrm{CD}=\mathrm{CD})_{m^{-}}$ & $m \geqq 1$ \\
\hline 748 & $-(\mathrm{CH}=\mathrm{CH})_{n^{-}} \quad n \geqq 6$ & between $-(\mathrm{CD}=\mathrm{CD})_{m^{-}}$ & $m \geqq 1$ \\
\hline & cis C-D out-of-plane deformation & & \\
\hline 653 & $-(\mathrm{CD}=\mathrm{CD})_{1^{-}}$ & between $-(\mathrm{CH}=\mathrm{CH})_{n^{-}}$ & $n \geqq 2$ \\
\hline 626 & $-(\mathrm{CD}=\mathrm{CD})_{1^{-}}$ & between $-(\mathrm{CH}=\mathrm{CH})_{1^{-}}$ & \\
\hline 600 & $-(\mathrm{CD}=\mathrm{CD})_{2^{-}}$ & between $-(\mathrm{CH}=\mathrm{CH})_{n^{-}}$ & $n \geqq 1$ \\
\hline 580 & $-(\mathrm{CD}=\mathrm{CD})_{3^{-}}$ & between $-(\mathrm{CH}=\mathrm{CH})_{n^{-}}$ & $n \geqq 1$ \\
\hline 562 & $-(C D=C D)_{4^{-}}$ & between $-(\mathrm{CH}=\mathrm{CH})_{n^{-}}$ & $n \geqq 1$ \\
\hline 551 & $-(\mathrm{CD}=\mathrm{CD})_{5^{-}}$ & between $-(\mathrm{CH}=\mathrm{CH})_{n^{-}}$ & $n \geqq 1$ \\
\hline 546 & $-(\mathrm{CD}=\mathrm{CD})_{m^{-}}$ & between $-(\mathrm{CH}=\mathrm{CH})_{n^{-}}$ & $n \geqq 1$ \\
\hline
\end{tabular}

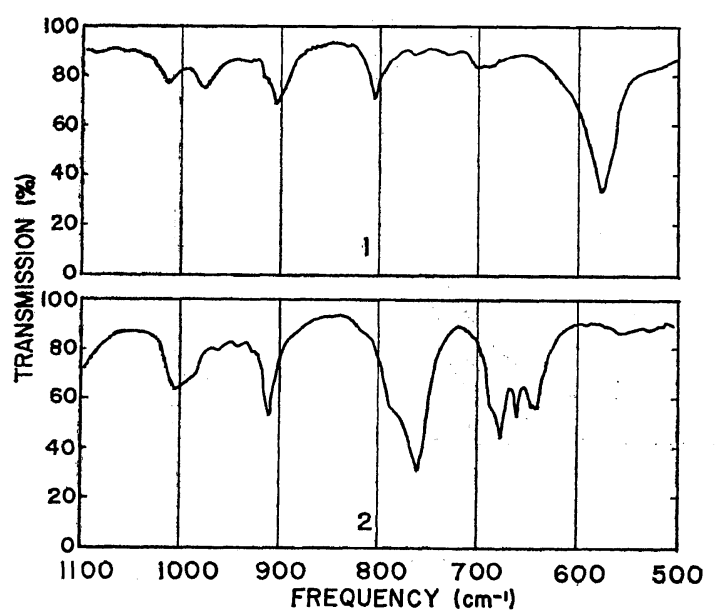

Figure 13. Infrared spectra of copoly(acetylene + acetylene- $d_{1}+$ acetylene- $d_{2}$ ) prepared at $-78^{\circ} \mathrm{C}: 1$, feed monomer ratio, $\mathrm{C}_{2} \mathrm{H}_{2}: \mathrm{C}_{2} \mathrm{HD}: \mathrm{C}_{2} \mathrm{D}_{2}=15: 47$ : $38 ; 2,67: 29: 4$.

acetylene- $d_{1}+$ acetylene- $d_{2}$ ) may have sequences consisting of odd number of C-H and/or C-D bonds. Frequency shift of C-H and C-D outof-plane due to such sequences may be larger than those in the cis I model but smaller than those in the cis II model, as may be expected from the calculated results of the cis I and cis II models. Spectra of the terpolymer prepared from different deuterated monomer compositions at $-78^{\circ} \mathrm{C}$ are shown in Figure 13. In fact, larger shifts than those in the copoly(acetylene+acetylene- $d_{2}$ ) are observed in the terpolymers. Several bands are tentatively assigned to the sequences which occur with high probabilties estimated from monomer compositions.

C-H out-of-plane deformation

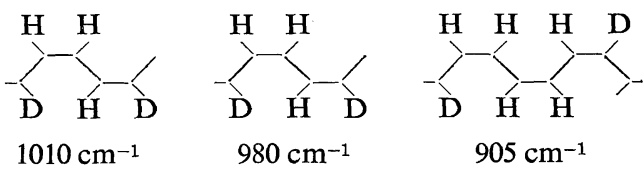

C-D out-of-plane deformation

Isolated C-D between C-H, $670 \mathrm{~cm}^{-1}$
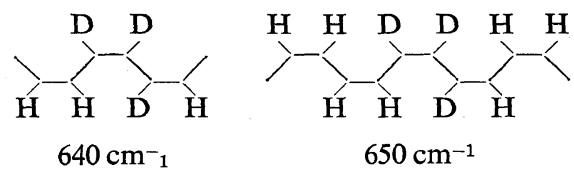

Polymer J., Vol. 2, No. 2, 1971 
The cis configuration of the two adjacent hydrogen atoms originated from an acetylene molecule clearly demonstrates that the cis-opening of the triple bond occurs in the polymerization reaction with the $\mathrm{Ti}\left(\mathrm{OC}_{4} \mathrm{H}_{9}\right)_{4}-\mathrm{Al}\left(\mathrm{C}_{2} \mathrm{H}_{5}\right)_{3}$ catalyst system at low temperature. Irreversible cistrans isomerization occurs at high polymerization temperature to the form trans sequences.

\section{TRANS AND CIS SEQUENCES IN POLY(ACETYLENE)}

As discussed in the previous section, the polymers obtained in a temperature range of -78 to $150^{\circ} \mathrm{C}$ contain both cis and trans configurations. In the spectra of various conjugated polyene, the splitting of the $\mathrm{C}-\mathrm{H}$ out-of-plane deformation band has been observed in the presence of a conjugated cis-trans diene group, ${ }^{5,12,13}$ triene, and tetraene. ${ }^{5}$ Ludde, et al., have shown that in the series of $\alpha, \omega$-diphenylpolyene of the general formula, $\mathrm{C}_{6} \mathrm{H}_{5}-(\mathrm{CH}=\mathrm{CH})_{n}-\mathrm{C}_{6} \mathrm{H}_{5} n=1$ to 4 , all isomers containing both a trans and a cis double bond(s) display a doublet in contrast to the all-trans forms in the region of $\mathrm{C}-\mathrm{H}$ out-ofplane deformation. They have considered that a trans $\mathrm{C}-\mathrm{C}$ double bond, either isolated or in conjugation with any other bond, gives rise to a vibrational frequency $\left(986-995 \mathrm{~cm}^{-1}\right)$ of $\mathrm{C}-\mathrm{H}$ out-of-plane deformation whereas conjugation of a cis to a trans double bond brings a new vibrational frequency $\left(945-971 \mathrm{~cm}^{-1}\right)$ of C-H (trans $\mathrm{C}=\mathrm{C}$ ) out-of-plane band.

In the spectra of poly(acetylene), there is neither band shift nor splitting of both trans and cis $\mathrm{C}-\mathrm{H}$ out-of-plane bands except in the spectrum of a cis polymer which contains a trace amount of trans configuration. The spectrum shows three very weak bonds at 1015,980 , and $940 \mathrm{~cm}^{-1}$. To make clear the assignments of these bands and to estimate the sequence length of cis and trans configurations in the poly(acetylene) chain, simplified calculations have been made for model chains consisting of repeating units of -(trans $\mathrm{CH}=\mathrm{CH})_{m}-(\text { cis } \mathrm{CH}=\mathrm{CH})_{n^{-}}$in which $m$ and $n$ were varied both from 1 to 10 . The calculations were again based on the in-phase mode of -(trans $\mathrm{CH}=\mathrm{CH})_{m^{-}}$and $-(\text {cis } \mathrm{CH}=\mathrm{CH})_{n^{-}}$using the same set of force constants used in the calculation of C-H out-of-plane bands of the copolymers. The result is shown in Figure 14. Comparison of the result with the observed bands leads to the assignments that $940 \mathrm{~cm}^{-1}$ band to -(trans $\mathrm{CH}=\mathrm{CH})_{1}$ - between $-(\text { cis } \mathrm{CH}=\mathrm{CH})_{n}$ - sequences, $980 \mathrm{~cm}^{-1}$ band to $-(\text { trans } \mathrm{CH}=\mathrm{CH})_{2}-$ between $-(\text { cis } \mathrm{CH}=\mathrm{CH})_{n^{-}}$sequences, and $1015 \mathrm{~cm}^{-1}$ band

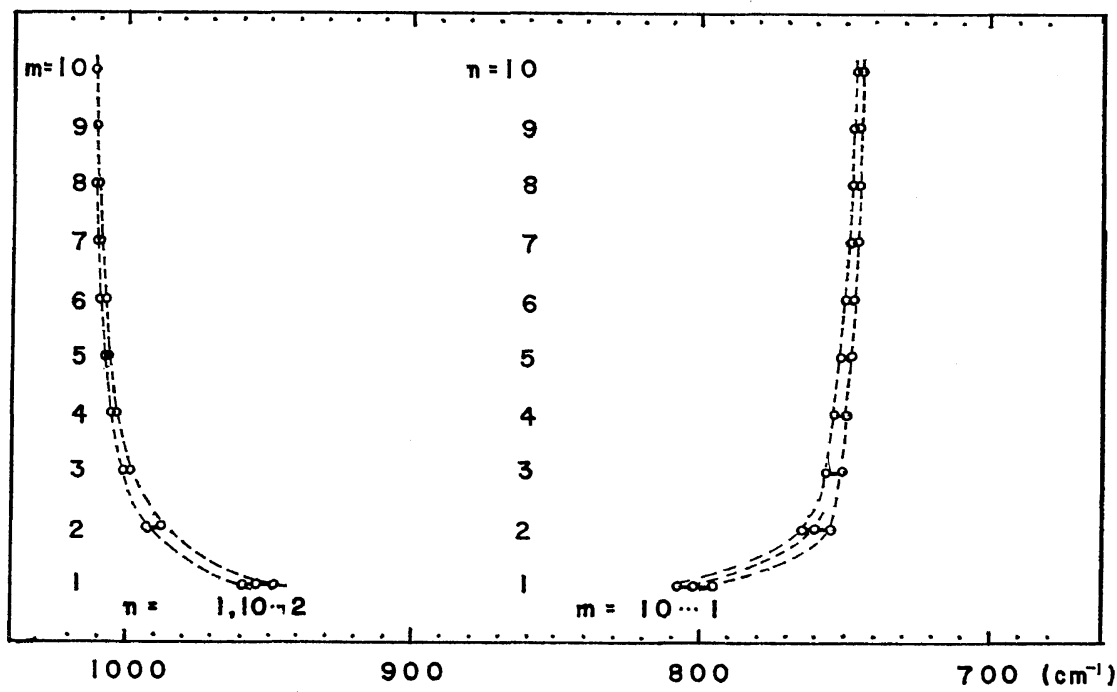

Figure 14. Locations of the calculated frequencies of $\mathrm{C}-\mathrm{H}$ out-of-plane deformation modes in cis-trans model copolymers. Repeating unit is $-(\text { trans } \mathrm{CH}=\mathrm{CH})_{m}-($ cis $\mathrm{CH}=$ $\mathrm{CH})_{n^{-}}$. 
to $-(\text { trans } \mathrm{CH}=\mathrm{CH})_{m^{-}}-(m \geq 2$, between $-($ cis $\mathrm{CH}$ $=\mathrm{CH})_{n}$ - sequences. The result of the calculation indicates that a band is expected in the vicinity of $805 \mathrm{~cm}^{-1}$ which should be assigned to the cis $\mathrm{C}-\mathrm{H}$ out-of-plane deformation corresponding to $-(\text { cis } \mathrm{CH}=\mathrm{CH})_{1}$ - between $-(\text { trans } \mathbf{C H}=\mathrm{CH})_{n}$ sequences. The band, however, could not be found in the region of $805 \mathrm{~cm}^{-1}$. This suggests that there is no isolated cis unit in trans sequences.

Acknowledgment. The authors wish to express their indebtedness to Prof. S. Maeda of the Tokyo Institute of Technology, and to Prof. T. Shimanouchi and Dr. M. Tasumi of the University of Tokyo for helpful discussions, and to Messrs. H. C. Pyun and T. Ito for the preparation of poly(acetylene) films.

\section{REFERENCES}

1. G. Natta, G. Mazzanti, and P. Corradini, Rend. Accad. Nazl. Lincei, (8) 25, 2 (1958).

2. W. H. Watson, Jr., W.C. McMordie, Jr., and L. G. Lands, J. Polym. Sci., 55, 137 (1961).

3. L. B. Luttinger, J. Org. Chem., 27, 1591 (1962).

4. P. Coradini, Rend. Accad. Nazl. Lincei, (8) 25, 517 (1958).

5. K. Lunde and L. Zechmeister, Acta chim. Scand., 8, 1421 (1954).

6. L. J. Bellamy, "The Infrared Spectra of Complex Molecules" John Wiley and Sons, Inc., New York, N.Y., 1954.
7. J. E. Lennard-Jones, Proc. Roy. Soc. (London), A158, 280 (1937).

8. H. Kuhn, J. Chem. Phys., 17, 1198 (1949).

9. Y. Ooshika, J. Phys. Soc., Japan, 12, 1246 (1950).

10a. E. R. Lippincott, C. E. White, and J. P. Sibilis, J. Amer. Chem. Soc., 80, 2926 (1958).

10b. E. R. Lippincott, W. R. Feairheller, Jr., and C. E. White, J. Amer. Chem. Soc., 81, 1316 (1959).

11. J. C. H. Hwa, P. L. de Benneville, and H. J. Sims, J. Amer. Chem. Soc., 82, 2537 (1960).

12. J. E. Jackson, R. F. Paschke, W. Talberg, H. M. Boyd, and D. H. Wheeler, J. Amer. Oil Soc., 29, 229 (1952).

13. W. D. Celmer and I. A. Solomons, J. Amer. Chem. Soc., 75, 3430 (1953).

14. F. D. Kleist and N. R. Byrd, J. Polym. Sci., Part A-1, 7, 3419 (1969).

15. S. Ikeda, Kogyo Kagaku Zasshi (J. Chem. Soc. Japan Ind. Chem. Sect.), 70, 1880 (1967).

16. S. Ikeda and A. Tamaki, Preprints, International Symposium on Macromolecular Chemistry, Tokyo-Kyoto, 1966, I-124.

17. K. Higashiura and M. Oiwa, Kogyo Kagaku Zasshi (J. Chem. Soc. Japan. Ind. Chem. Sect.), 69, 109 (1966).

18. G. F. Woods and L. H. Schwartzman, J. Amer. Chem. Soc., 71, 1396 (1949).

19. F. Sondheimer, D. A. Ben-Efraim, and R. Wolovsky, J. Amer. Chem. Soc., 83, 1675 (1961).

20. A. D. Mebane, J. Amer. Chem. Soc., 74, 5227 (1952). 